\title{
Non-fatal repetition of self-harm in Taipei City, Taiwan: cohort study
}

\author{
Chi-Leung Kwok, Paul S. F. Yip, David Gunnell, Chian-Jue Kuo and Ying-Yeh Chen
}

\section{Background}

Repeat self-harm is an important risk factor for suicide. Few studies have explored risk factors for non-fatal repeat self-harm in Asia.

\section{Aims}

To investigate the risk of non-fatal repeat self-harm in a large cohort of patients presenting to hospital in Taipei City, Taiwan.

\section{Method}

Prospective cohort study of 7601 patients with self-harm presenting to emergency departments (January 2004-

December 2006). Survival analysis was used to examine the rates, timing and factors associated with repeat self-harm.

\section{Results}

In total $778(10.2 \%)$ patients presented to hospital with one or more further episodes of self-harm. The cumulative risk of non-fatal repetition within 1 year of a self-harm episode was 9.3\% (95\% Cl 8.7-10.1). The median time to repetition within 1 year was 105 days. Females had a higher incidence of repeat self-harm than males (adjusted hazard ratio 1.25, 95\% Cl 1.05-1.48) but males had shorter median time to repetition (107 v. 80 days). Other independent risk factors for repeat self-harm within 1 year of an index episode were: young age, self-harm by medicine overdose and increasing number of repeat episodes of self-harm.

\section{Conclusions}

The risk of non-fatal repeat self-harm in Taipei City is lower than that seen in the West. Risk factors for repeat non-fata self-harm differ from those for fatal self-harm. The first 3 months after self-harm is a crucial period for intervention.

\section{Declaration of interest}

None.
Non-fatal self-harm is one of the strongest risk factors for further acts of suicidal behaviour. ${ }^{1,2}$ Other consistently reported sociodemographic risk factors for non-fatal self-harm include female gender, younger age and being unmarried. ${ }^{3,4}$ Risk of repetition is highest in the first year after an episode of self-harm, with an estimated median proportion of $15-16 \%$ of individuals repeating. ${ }^{1}$ Knowledge of these risk factors is crucial to provide an evidence base to inform risk assessment and public health prevention strategies. ${ }^{5}$ However, it is unclear whether the risk factors identified in Western populations or the timing of risk are similar in Asians.

Unlike the high rates of repeat self-harm found in the West, figures reported in Asian countries, although scarce, are generally much lower. ${ }^{6-8}$ For example, a study conducted in rural Taiwan reported a 5.7\% 1-year risk of non-fatal repetition. ${ }^{7}$ Studies from Sri Lanka, a low-/middle-income country, indicate that less than $10 \%$ of patients who self-harm have done so previously. ${ }^{6,8}$ A possible contributor to the difference in repetition risk may be the frequent use of pesticides for self-poisoning in many Asian countries. ${ }^{9-12}$ Case fatality following pesticide poisoning is considerably higher than that following medicine overdose, meaning a high proportion of individuals at risk of repetition are removed from the population at risk of repetition in Asia.

Recent evidence from Hong Kong shows a different picture. $^{13}$ The reported 6-month repetition rate was $16.7 \%$, a figure similar to findings from the West, with self-poisoning by medicine (mainly painkillers and sleeping pills) being the most common method used. However, the Hong Kong study recruited cases from a single hospital and had a small sample size $(n=92)$. A recent study based on Taiwan's national health insurance data-set found a low rate of repeat self-harm $(8 \%)$ within the first year of follow-up. ${ }^{14}$ However, this study relied on insurance claim data to ascertain self-harm cases and was based on hospital admissions only. Specifying cause of injury/disease (such as self-harm or accident) is not mandatory for insurance reimbursement in Taiwan and this is likely to have led to an underestimate of the incidence of self-harm and self-harm repetition. ${ }^{15}$ No representative large-scale, community-based study of the risk of repeat self-harm in an urban area of a high-income country in Asia has been published; risk of non-fatal repetition in such a setting might be predicted to be different from that of rural or low- and middle-income Asian countries.

A less-studied area is the timing of repetition. Examining the time to repetition among different subgroups might help identify patient characteristics associated with a higher risk of repetition soon after an attempt, thereby facilitating targeted and specific interventions. A multicentre study in the UK has estimated that among individuals who repeat self-harm within 1 year, the median time to repetition is 73.5 days, with $10 \%$ repeating within 5 days. ${ }^{16}$ No similar study can be found in Asia, where nearly $60 \%$ of the world's suicides occur. ${ }^{11}$

The current study focused on non-fatal repetition of self-harm in a cohort of patients presenting to the emergency department in Taipei City, Taiwan. The study investigated the risk and timing of non-fatal repetition, as well as associated risk factors, especially within the first year. In an earlier study of suicide risk in this cohort we found that the key risk factors for suicide were being male, aged $>45$ years and use of hanging or charcoal burning in the index episode of self-harm. ${ }^{15}$

\section{Method}

\section{Study population}

Patients presenting to emergency departments after an episode of self-harm were identified from the Taipei City self-harm surveillance system, a service-based suicide prevention programme run by the city's Suicide Research and Prevention Centre. Taipei City (population 2.6 million) is Taiwan's capital city. All emergency departments in the city, including 8 universityaffiliated medical centres and 18 regional general hospitals, were 
required to report any presentation of self-harm/suicide regardless of whether the person was admitted. Self-harm includes attempts regardless of the degree of suicide intent or medical seriousness. Emergency department staff are required to complete a structured case-note sheet for all self-harm presentations. The form records basic sociodemographic data and method of self-harm. These are then forwarded to the surveillance system of the Suicide Research and Prevention Centre. Case managers from the centre then followed up the reported self-harm cases and provided aftercare. Suicide risk assessment and supportive psychotherapy were offered. Depending on the estimated risk of suicide, the follow-up frequency may range between two to three times per week and one to two times a month (further information about the content of services provided by case managers available at http://tspc.health.gov.tw/about4.html). Further referral to psychiatrists or the social welfare system was provided as needed.

Altogether, 8343 people presenting with self-harm to emergency departments in Taipei City between January 2004 and December 2006 were identified. Individuals who died in the index attempt $(n=202,2.4 \%)$ were aged $\leqslant 15$ years $(n=60,0.7 \%)$ and were not Taiwanese citizens $(n=98,1.2 \%)$; or for whom national identity numbers were not available $(n=382,4.6 \%)$ were excluded from the analysis. Our analysis is therefore based on a sample of 7601 self-harm cases. A patient's first self-harm presentation during this period was defined as their index episode. The unique national identity number was used to identify repeat episodes. The national identification number in Taiwan is issued at the time of birth registration; it is unique to each individual. This number is used in virtually all activities and government functions that require verification of identity (e.g. healthcare, school admission, voting, marriage registration, opening a bank account).

All patients were followed up to the end of 2006, no matter when they first presented. Methods of self-harm were categorised into solid/liquid poisoning, self-cutting/piercing, concurrent use of medication overdose and self-cutting/piercing, charcoal burning, hanging, and other methods. Solid/liquid poisoning was further classified into medicine, pesticide and other poisons. Except for concurrent use of medication and self-cutting/piercing, if an individual used more than one method of self-harm, we used a hierarchical algorithm based on method lethality. For example, if a person used hanging combined with medication overdose, hanging was identified as the key method of self-harm as it is a more lethal method than medication overdose. The study was approved by the institutional review board of Taipei City Hospital (TCHIRB-1001202-E).

\section{Statistical analysis}

All patients registered on the surveillance system regardless of length of follow-up period were included in the survival analysis. The Kaplan-Meier method was used to estimate risk of repetition and median time to repetition following index episode. The risks were given by Kaplan-Meier cumulative failure functions $\left(F_{(t)}=1-S_{(t)}\right)$, with associated $95 \%$ confidence intervals.

Factors associated with repetition within 1 year were investigated by proportional rates/means models. ${ }^{17}$ These models were Cox proportional hazard type models, ${ }^{18}$ specifically for recurrence data. The proposed method does not restrict to first repetition following index episode. All repeat episodes for a given individual were included, such that information could be fully utilised to estimate the risk factors associated with repeat self-harm. Inference was based on robust sandwich variance estimates such that the models did not require any specific structure of dependence among recurrent events (non-fatal repetitions) within the same patients. However, time-varying covariates were allowed, which gave us the opportunity to investigate the hazard ratio (HR) of patients with increasing number of repeat self-harm presentations. Univariable models were first fitted and the interaction effect of each factor with gender was also examined to determine whether there were any gender differences in the associations. A multivariable model was then used to identify independent risk factors of non-fatal repetition within 1 year.

The median time to repetition in this study was also estimated through the Kaplan-Meier method and was restricted to patients who repeated within 1 year of the index event. For example, if a 1 -year risk of $20 \%$ was observed through the Kaplan-Meier curve, the median time to repetition was defined as the time when $10 \%$ of patients with self-harm had repeated.

All analyses were conducted using SAS version 9.3 for Windows. Patients were right-censored if they died by any cause during the follow-up period. The assumption of proportional hazard was tested by plotting standardised score process for each covariate, using the ASSESS statement of PROC PHREG in SAS. ${ }^{19}$ No evidence of violation was detected.

\section{Results}

\section{Patient characteristics}

The annual rate of non-fatal self-harm in Taipei City during 20042006 was 135.2 per 100000 population (male: 81.5; female: 185.2). Based on the sociodemographic characteristics of patients during their index episodes (Table 1), most patients were female, with a female-to-male ratio of 2.28:1. Their ages ranged from 15 to 96 years, and half of the patients were $25-44$ years old. The mean age was 38.22 years (s.d. $=18.36$ ) for males and 35.31 years $($ s.d. $=14.23)$ for females. The follow-up period ranged from 1 day to 3 years, with an average of 1.43 years $($ s.d. $=0.82)$. Patients with self-harm in Taipei City were more likely to be nevermarried. The most common means of self-harm in the index episode was solid/liquid poisoning by medication overdose $(57.4 \%)$, followed by self-cutting/piercing $(22.0 \%)$ and charcoal burning (5.8\%).

Approximately $10 \% \quad(n=778 ; 611$ female, 167 male $)$ of patients had one or more self-harm attempts after the index episode (Table 1). Pearson's $\chi^{2}$ was used to investigate differences between the single-episode group and repeat-episode group. The repeat-episode group tended to be female, younger, single or divorced/separated, and used medicine or medicine and selfcutting/piercing combined as their means of self-harm. Among the 778 patients who repeat self-harmed, $555(71.34 \%)$ repeated once, $133(17.10 \%)$ twice, $52(6.68 \%)$ three times and 38 $(4.88 \%)$ repeated four or more times within the 3 years (maximum) of follow-up. In total, 1185 repeat self-harm episodes were recorded.

\section{Risk of non-fatal repetition}

Figure 1 shows the probability of surviving a non-fatal repetition from the Kaplan-Meier analysis and Table 2 summarises the 1 -year risk across different subgroups estimated using the Kaplan-Meier method. For the overall sample, the risk of repetition was $9.3 \%(95 \%$ CI $8.7-10.1)$ within 1 year following an index episode and $14.8 \%$ (95\% CI 13.5-16.1) during the whole follow-up period. The risk of repetition within 1 year was $10.4 \%$ (95\% CI 9.5-11.3) for females and 6.9\% (95\% CI 5.9-8.1) for males (Table 2) (unadjusted $\mathrm{HR}=1.47$, 95\% CI 1.19-1.81, $P=0.0003)$. The cumulative risk during the entire follow-up period for females and males was $17.1 \%$ (95\% CI 15.4-18.9) and $9.7 \%$ (95\% CI 8.2-11.4) respectively, and was consistently higher in females than in males (Fig. 1).

We also plotted the Kaplan-Meier survivor functions for those who repeatedly self-harmed (Fig. 2). The risk of repetition 
increased sharply with increasing number of repeat self-harm presentations $\left(\chi^{2}\right.$ (trend $)=802.94$, d.f. $\left.=1, P<0.0001\right)$. The 1 -year repetition risk increased to $29.4 \%$ (95\% CI 26.0-33.2) among those who had repeated once already (i.e. patients with two selfharm presentations) (unadjusted $\mathrm{HR}=5.86,95 \%$ CI $4.88-7.03$, $P<0.0001)$ and was $45.2 \%$ (95\% CI 37.8-53.2) among those who had repeated twice (unadjusted HR $=13.55$, 95\% CI 10.3717.70, $P<0.0001$ ), and then to $62.7 \%$ (95\% CI 54.1-71.3) for patients who presented four times or more (unadjusted $\mathrm{HR}=24.69,95 \%$ CI $17.86-34.13, P<0.0001)$. There was no evidence of a gender difference in risk of repetition in relation to the number of repeat episodes $\left(\chi_{\text {(interaction) }}^{2}=3.19\right.$, d.f. $=3$, $P=0.36)$.

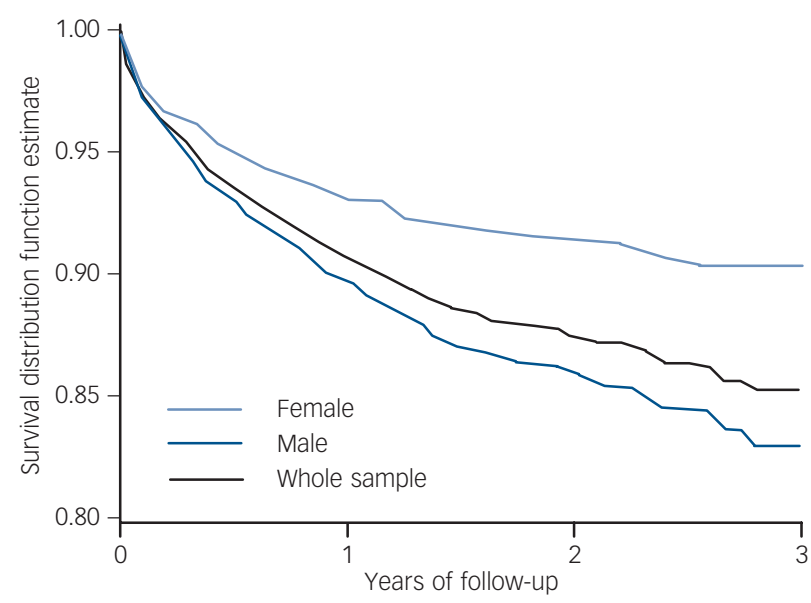

Fig. 1 Kaplan-Meier estimates of survival curve, for the whole sample and by gender.

\section{Factors associated with repetition}

Univariable models showed that the repetition risk differed across age groups $\left(\chi^{2}=40.35\right.$, d.f. $\left.=3, \quad P<0.0001\right)$, marital status $\left(\chi^{2}=24.05, \quad\right.$ d.f. $\left.=3, \quad P<0.0001\right)$ and method of self-harm $\left(\chi^{2}=55.25\right.$, d.f. $\left.=7, P<0.0001\right)$. The hazard of repeat self-harm was lower among those aged 45-64 years and $>65$ years than the younger age groups (Table 3 ). Compared with those aged 45-64 years, the unadjusted HR was 0.42 (95\% CI $0.24-0.72)$ in patients aged $>65$, whereas for those aged $25-44$ years it was 1.66 (95\% CI 1.27-2.16). Divorced/separated or never-married individuals had a higher risk of repetition when compared with those who were married or cohabitated. Regarding means of self-harm, medication overdose, self-cutting/piercing and the

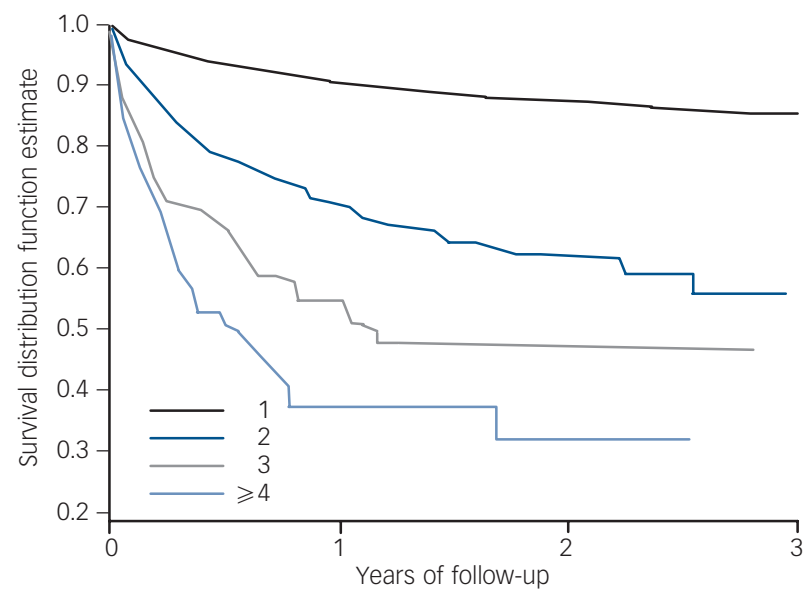

Fig. 2 Kaplan-Meier estimates of survival curve, stratified by number of previous self-harm episodes.

\begin{tabular}{|c|c|c|c|c|c|c|}
\hline & $\begin{array}{l}\text { All patients } \\
n(\%)\end{array}$ & $\begin{array}{c}\text { Single-episode group } \\
n(\%)\end{array}$ & $\begin{array}{l}\text { Repeat-episode group } \\
\qquad n(\%)\end{array}$ & $\begin{array}{c}\text { Pearson } \\
\chi^{2}\end{array}$ & d.f. & $P$ \\
\hline \multicolumn{7}{|l|}{ Gender } \\
\hline Both & $7601(100)$ & $6823(100)$ & $778(100)$ & \multirow[t]{3}{*}{33.17} & \multirow[t]{3}{*}{1} & \multirow[t]{3}{*}{$<0.0001$} \\
\hline Female & $5285(69.5)$ & $4674(68.5)$ & $611(78.5)$ & & & \\
\hline Male & $2316(30.5)$ & 2149 (31.5) & $167(21.5)$ & & & \\
\hline Age group ${ }^{a}$ & $7583(100)$ & $6805(100)$ & $778(100)$ & \multirow[t]{5}{*}{49.86} & \multirow[t]{5}{*}{3} & \multirow[t]{5}{*}{$<0.0001$} \\
\hline $15-24$ years & $1956(25.8)$ & $1732(25.5)$ & $224(28.8)$ & & & \\
\hline 25-44 years & $3778(49.8)$ & $3338(49.1)$ & $440(56.6)$ & & & \\
\hline 45-64 years & $1321(17.4)$ & $1226(18.0)$ & $95(12.2)$ & & & \\
\hline $65+$ years & $528(7.0)$ & $509(7.5)$ & $19(2.4)$ & & & \\
\hline Marital status ${ }^{b}$ & $6069(100)$ & $5328(100)$ & $741(100)$ & \multirow[t]{5}{*}{23.82} & \multirow[t]{5}{*}{3} & \multirow[t]{5}{*}{$<0.0001$} \\
\hline Married/cohabitating & $2132(35.1)$ & $1913(35.9)$ & $219(29.6)$ & & & \\
\hline Never married & $2772(45.7)$ & $2399(45.0)$ & $373(50.3)$ & & & \\
\hline Divorced/separated & $996(16.4)$ & $855(16.0)$ & $141(19.0)$ & & & \\
\hline Widowed & $169(2.8)$ & $161(3.0)$ & $8(1.1)$ & & & \\
\hline Means of self-harm in index episode ${ }^{c}$ & $7599(100)$ & $6821(100)$ & $778(100)$ & 44.24 & 7 & $<0.0001$ \\
\hline \multicolumn{7}{|l|}{ Solid/liquid poisoning } \\
\hline Medicine & $4365(57.4)$ & $3898(57.1)$ & $467(60.0)$ & & & \\
\hline Pesticide & $122(1.6)$ & $117(1.7)$ & $5(0.6)$ & & & \\
\hline Other poisons & $303(4.0)$ & $282(4.1)$ & $21(2.7)$ & & & \\
\hline Self-cutting/piercing & $1672(22.0)$ & $1498(22.0)$ & $174(22.4)$ & & & \\
\hline Medicine + self-cutting/piercing & $295(3.9)$ & $240(3.5)$ & $55(7.1)$ & & & \\
\hline Charcoal burning & $440(5.8)$ & $410(6.0)$ & $30(3.9)$ & & & \\
\hline Hanging & $83(1.1)$ & $77(1.1)$ & $6(0.8)$ & & & \\
\hline Other $^{\text {d }}$ & $319(4.2)$ & $299(4.4)$ & $20(2.6)$ & & & \\
\hline
\end{tabular}




\begin{tabular}{|c|c|c|c|}
\hline & \multicolumn{3}{|c|}{ Repetition risk, \% (95 Cl) } \\
\hline & Male & Female & Total \\
\hline All & $6.9(5.9-8.1)$ & $10.4(9.5-11.3)$ & $9.3(8.7-10.1)$ \\
\hline \multicolumn{4}{|l|}{ Age group } \\
\hline $15-24$ years & $6.7(5.0-8.9)$ & $12.4(10.6-14.4)$ & $10.5(9.1-12.0)$ \\
\hline 25-44 years & $8.3(6.6-10.5)$ & $11.3(10.1-12.6)$ & $10.5(9.5-11.6)$ \\
\hline $45-64$ years & $6.7(4.5-9.8)$ & $6.7(5.2-8.8)$ & $6.7(5.4-8.4)$ \\
\hline $65+$ years & $3.2(1.6-6.2)$ & $3.8(1.9-7.6)$ & $3.5(2.1-5.6)$ \\
\hline \multicolumn{4}{|l|}{ Marital status } \\
\hline Married/cohabitating & $7.3(5.4-9.8)$ & $10.6(9.0-12.5)$ & $9.6(8.3-11.1)$ \\
\hline Never married & $8.6(6.9-10.7)$ & $14.3(12.7-16.2)$ & $12.4(11.1-13.8)$ \\
\hline Divorced/separated & $10.3(6.5-16.0)$ & $14.3(11.8-17.2)$ & $13.4(11.3-15.9)$ \\
\hline Widowed & $9.6(3.2-27)$ & $1.6(0.4-6.2)$ & $3.2(1.4-7.6)$ \\
\hline \multicolumn{4}{|l|}{$\begin{array}{l}\text { Means of self-harm in index episode } \\
\text { solid/liguid poisoning }\end{array}$} \\
\hline \multicolumn{4}{|l|}{ Solid/liquid poisoning } \\
\hline Medicine & $8.0(6.4-9.8)$ & $10.4(9.3-11.5)$ & $9.8(8.9-10.7)$ \\
\hline Pesticide & $4.8(1.5-14.3)$ & $2.4(0.3-16.1)$ & $4.0(1.5-10.4)$ \\
\hline Other poisons & $7.9(4.2-14.8)$ & $7.2(4.0-12.8)$ & $7.5(4.9-11.5)$ \\
\hline Self-cutting/piercing & $6.2(4.3-8.9)$ & $10.4(8.6-12.4)$ & $9.1(7.7-10.7)$ \\
\hline Medicine + self-cutting/piercing & $5.1(1.7-15.0)$ & $20.3(15.5-26.4)$ & $17.4(13.3-22.5)$ \\
\hline Charcoal burning & $5.5(3.0-9.8)$ & $7.7(4.6-12.7)$ & $6.5(4.4-9.6)$ \\
\hline Hanging & $4.5(1.1-16.9)$ & $6.3(1.6-22.8)$ & $5.4(2.1-13.8)$ \\
\hline Other $^{\mathrm{a}}$ & $5.7(2.9-11.2)$ & $5.3(2.5-10.8)$ & $5.5(3.3-9.0)$ \\
\hline
\end{tabular}

\begin{tabular}{|c|c|c|c|c|c|c|}
\hline & \multicolumn{3}{|c|}{ Univariable model } & \multicolumn{3}{|c|}{ Multivariable model } \\
\hline & \multirow[b]{2}{*}{ Unadjusted HR (95\% Cl) } & \multicolumn{2}{|c|}{ Test for heterogeneity } & \multirow[b]{2}{*}{ Adjusted HR (95\% Cl) } & \multicolumn{2}{|c|}{ Test for heterogeneity } \\
\hline & & (d.f.) & $P$ & & (d.f.) & $P$ \\
\hline Gender & & $13.22(1)$ & 0.0003 & & $6.76(1)$ & 0.0093 \\
\hline Male & 1.00 & & & 1.00 & & \\
\hline Female & $1.47(1.19-1.81)^{\star}$ & & & $1.26(1.06-1.49)^{\star *}$ & & \\
\hline Age group & & $40.35(3)$ & $<0.0001$ & & $20.85(3)$ & 0.0001 \\
\hline $15-24$ years & $1.55(1.17-2.05)^{\star}$ & & & $1.17(0.87-1.55)$ & & \\
\hline $25-44$ years & $1.66(1.27-2.16)^{*}$ & & & $1.30(1.03-1.65)^{\star *}$ & & \\
\hline $45-64$ years & 1.00 & & & 1.00 & & \\
\hline $65+$ years & $0.42(0.24-0.72)^{*}$ & & & $0.48(0.30-0.79)^{*}$ & & \\
\hline Marital status & & $24.05(3)$ & $<0.0001$ & & 6.85 (3) & 0.0769 \\
\hline Married/cohabitating & 1.00 & & & 1.00 & & \\
\hline Never married & $1.39(1.15-1.69)^{*}$ & & & $1.18(0.97-1.42)^{\star \star \star}$ & & \\
\hline Divorced/separated & $1.52(1.17-1.96)^{\star}$ & & & $1.22(1.00-1.48)^{\star \star \star}$ & & \\
\hline Widowed & $0.36(0.16-0.81)^{\star *}$ & & & $0.62(0.29-1.32)$ & & \\
\hline Previous means of self-harm ${ }^{a}$ & & $55.25(7)$ & $<0.0001$ & & $26.09(7)$ & 0.0005 \\
\hline \multicolumn{7}{|l|}{ Solid/liquid poisoning } \\
\hline Medicine & 1.00 & & & 1.00 & & \\
\hline Pesticide & $0.29(0.11-0.77)^{\star *}$ & & & $0.52(0.21-1.32)$ & & \\
\hline Other poisons & $0.71(0.47-1.07)$ & & & $0.79(0.53-1.19)$ & & \\
\hline Self-cutting/piercing & $0.99(0.83-1.19)$ & & & $0.97(0.82-1.15)$ & & \\
\hline Medicine + self-cutting/piercing & $1.86(1.43-2.42)^{*}$ & & & $1.50(1.15-1.94)^{\star}$ & & \\
\hline Charcoal burning & $0.56(0.39-0.81)^{*}$ & & & $0.62(0.43-0.89)^{*}$ & & \\
\hline Hanging & $0.41(0.16-1.07)^{\star \star *}$ & & & $0.56(0.22-1.40)$ & & \\
\hline Other ${ }^{c}$ & $0.56(0.36-0.88)^{\star *}$ & & & $0.69(0.44-1.06)^{\star \star \star}$ & & \\
\hline \multicolumn{2}{|l|}{ Number of repeat self-harm presentations } & $802.94(1)^{b}$ & $<0.0001$ & & $670.78(1)^{b}$ & $<0.0001$ \\
\hline 1 & 1.00 & & & 1.00 & & \\
\hline 2 & $5.86(4.88-7.03)^{\star}$ & & & $4.49(3.71-5.43)^{\star}$ & & \\
\hline 3 & $13.55(10.37-17.70)^{*}$ & & & $10.01(7.61-13.15)^{*}$ & & \\
\hline 4 or more & $24.69(17.86-34.13)^{*}$ & & & $16.75(12.40-22.62)^{\star}$ & & \\
\hline \multicolumn{7}{|c|}{$\begin{array}{l}\text { a. Unlike means of self-harm in index episode (which was fixed to an individual), it referred to a time-varying (or episode-varying) covariate which may change when the individual } \\
\text { repeated their act of self-harm. } \\
\text { b. Test for trend. } \\
\text { c. Other included jumping from a height, domestic gas, drowning, head banging, vehicle exhaust gas, lying on the rails, injecting unknown substances, self-immolation, tongue } \\
\text { biting, hit by a car, swallowing coins, electric shock, ingesting poisonous plants, jumping out of a car on a highway, using a firearm, other unspecific methods. } \\
* P<0.01 ; * P<0.05 ; * * P<0.1 \text {. }\end{array}$} \\
\hline
\end{tabular}




\begin{tabular}{|c|c|c|c|}
\hline & \multicolumn{3}{|c|}{ Median time, days $(95 \% \mathrm{Cl})$} \\
\hline & Male & Female & Total \\
\hline All & $80(48-137)$ & $107(89-124)$ & $105(88-121)$ \\
\hline \multicolumn{4}{|l|}{ Age group } \\
\hline $15-24$ years & $50(15-137)$ & $97(71-122)$ & $88(56-115)$ \\
\hline $25-44$ years & $130(52-194)$ & $111(83-128)$ & $112(84-130)$ \\
\hline $45-64$ years & $89(20-190)$ & $135(85-236)$ & $123(83-177)$ \\
\hline $65+$ years & $39(1-196)$ & $233(99-321)$ & $99(11-283)$ \\
\hline \multicolumn{4}{|l|}{ Marital status } \\
\hline Married/cohabitation & $89(29-171)$ & $133(111-190)$ & $126(104-157)$ \\
\hline Never married & $99(50-151)$ & $105(80-134)$ & $104(80-125)$ \\
\hline Divorced/separated & $131(52-284)$ & $106(74-144)$ & $118(78-160)$ \\
\hline Widowed & $55(11-196)$ & 132 (99-NA) & $99(11-196)$ \\
\hline \multirow{2}{*}{\multicolumn{4}{|c|}{$\begin{array}{l}\text { Previous means of self-harm } \\
\text { Solid/liquid poisoning }\end{array}$}} \\
\hline & & & \\
\hline Medicine & 73 (39-137) & $116(90-135)$ & $111(84-128)$ \\
\hline Pesticide & $114(1-364)$ & 126 (NA-NA) & $126(1-364)$ \\
\hline Other poisons & $151(92-321)$ & $95(7-343)$ & $151(49-310)$ \\
\hline Self-cutting/piercing & $70(45-250)$ & 89 (70-144) & 88 (69-133) \\
\hline Medicine + self-cutting/piercing & $1(1-19)$ & $107(58-194)$ & $99(49-187)$ \\
\hline Charcoal burning & $40(1-352)$ & $83(17-309)$ & $52(17-275)$ \\
\hline Hanging & $11(1-\mathrm{NA})$ & 129 (22-NA) & $22(1-129)$ \\
\hline Other $^{\mathrm{a}}$ & $176(168-339)$ & $131(35-205)$ & $175(86-336)$ \\
\hline
\end{tabular}

concurrent use of medication overdose and self-cutting/piercing were associated with elevated risk of self-harm repetition. There was no evidence that the risk of repeat self-harm in relation to the risk factors investigated differed in males $v$. females $\left(P_{\text {(interaction) }}=0.29-0.87\right)$.

After adjusting for other variables, the effect of marital status on future risk of non-fatal repetition was greatly attenuated. Associations with gender, age and method of self-harm persisted, although these too were somewhat weaker than those seen in the univariable analysis (Table 3). Patients who adopted concurrent use of medication and self-cutting/piercing have a 50\% higher risk (adjusted HR $=1.50 ; 95 \%$ CI 1.15-1.94) than those who use medication poisoning. History of self-harm was still the strongest risk factor. Increasing number of repeat self-harm presentations after the index episode was strongly associated with non-fatal repetition.

\section{Timing of non-fatal repetition}

Table 4 shows the estimates of the median time to repetition, restricted to those who repeated within 1 year. For the entire patient cohort, the estimated median time to non-fatal repetition among patients who repeated within 1 year following an index episode was 105 days (95\% CI 88-121). The risk was highest within the days immediately after the index self-harm episode. Approximately 1 in 10 patients who repeated did so within 4 days.

Although the repetition risk was higher in females than in males, males tended to repeat earlier than females. The median time to repetition in males ( 80 days; $95 \%$ CI 48-137) was 4 weeks shorter than that in females (107 days; 95\% CI 89-124), but the statistical evidence for the difference was marginal $(P=0.09)$. The gender difference in time to repetition was most marked in older adults, with older men repeating the fastest (males aged $>65=39$ days, 95\% CI 1-196; females aged $>65=233$ days, 95\% CI 99-321; $P=0.0051)$. The median times to repetition were considerably shorter in males across all age groups, except those aged 25-44.

\section{Discussion}

\section{Main findings}

The risk of non-fatal repetition 1 year after an episode of self-harm in Taipei City was $9.3 \%$ - higher than that reported in previous studies from Taiwan ${ }^{7,14}$ but lower than findings in the West. ${ }^{1,16}$ The risk was particularly high within the first year following an episode of self-harm. Risk of repeat self-harm was higher in females than males, but males appeared to repeat their act more quickly. Risk of repeat self-harm was also higher in younger patients and those who used medication overdose or concurrent use of self-cutting and medication overdose in their last episode of self-harm. The risk of repeat self-harm increased markedly with increases in the number of repeat self-harm presentations after the index episode and tended to be associated with shorter intervals between episodes of self-harm.

\section{Strengths and limitations}

This is the largest investigation of non-fatal repeat self-harm among a representative cohort of patients in an urban setting in Asia. The large sample size meant we had sufficient statistical power to investigate risks of repetition in a number of different subgroups. Furthermore, as the study was based on patients presenting with self-harm to the emergency department and the surveillance register covered the whole of Taipei City, selection bias and loss to follow-up was reduced.

However, the study has a number of limitations. The surveillance system records only limited demographic information and details of the method used for self-harm. No information on risk factors identified in previous studies (e.g. unemployment, clinical diagnosis, childhood sexual or physical abuse) is recorded. ${ }^{13,16,20}$ The second limitation is that our cohort was based on people presenting to hospital emergency departments following self-harm; individuals who did not present to hospital or consult with private doctors would not be captured by the 
system, leading to underestimation of the risk of repeat self-harm. Last, movement out of the study catchment area by cohort members who left Taipei City may influence the estimated rate of self-harm repetition. However, only $2 \%$ of Taipei City residents move to other cities every year, so this is unlikely to have a major impact on our estimates. ${ }^{21}$

\section{Risk and timing of non-fatal repetition following self-harm}

Following index self-harm presentations to the emergency department, 9.3\% of patients repeated their act of non-fatal selfharm within 1 year and $14.8 \%$ did so within 3 years. If fatal cases are included, the 1-year rates of repetition in our sample would increase to $10.9 \% .{ }^{15}$ These figures were high when compared with previous findings from rural Asia or low- and middle-income Asian countries, with figures ranging from $3.0 \%$ to $9.5 \%,{ }^{7,8}$ but were lower than findings from the West where the risk of repetition within 1 year is approximately $15 \%{ }^{1}$

Although the risk of repeat self-harm was higher in females than males, we found some evidence that males tended to repeat sooner than females, a finding in keeping with a previous study from the UK. ${ }^{16}$ The estimated median time to repetition among those who repeated within 1 year in our study was 105 days (males, 80 days; females, 107 days); the UK finding was 73.5 days (males, 67.5 days; females, 84 days). The time to repetition seems to be particularly short (39 days) in older men ( $>65$ years). Few previous studies have explored timing of self-harm repetition, however both studies support the notion that the first 3 months following a self-harm episode had the highest elevated risk of repetition and was thus the critical period for intervention.

The pattern of non-fatal repetition by age was similar to previous studies across countries. The younger age group was associated with higher risk of repetition for both males and females. ${ }^{16,22}$ However, the proportion of middle and older age groups was higher in our self-harm cohort; approximately $24 \%$ of our cohort were 45 years or older; the equivalent figures in previous UK studies were less than $15 \% .{ }^{16,23}$ This may partially contribute to the lower rates of non-fatal repetition in our study, as older age groups are less likely to repeat self-harm.

Methods of self-harm in our Tapei City sample were different from those reported by Chen et al in their study of self-harm in rural Taiwan. ${ }^{7}$ In the index episode, a higher proportion of patients self-poisoned using medication and other chemicals in Taipei City $(61.6 \%)$ than in rural Taiwan $(43.9 \%)$ but this was compensated by the much smaller proportion for those who ingested pesticides $(1.6 \%$ v. $24.4 \%)$, probably due to its limited accessibility in urban areas. This might also explain the larger risk of non-fatal repetition in Taipei City. Pesticide ingestion was associated with a decreased risk of non-fatal repetition in rural Taiwan, ${ }^{7}$ and patients who overdosed were somewhat more likely to repeat. This may be due to the relatively higher case fatality of pesticide ingestion than medication overdose (case fatality for pesticides in Taiwan was estimated to be 5-10\%; medication overdose was generally lower than $5 \%) .{ }^{24-26}$ Our previous study on fatal repetition in this self-harm cohort shows that the risk of fatal repetition for those who self-harmed by pesticide was two times higher than the group who used medication overdose in the first year after the index episode. ${ }^{15}$ The highest-risk patients who self-poison with pesticides are therefore removed from the group at risk of repetition. Furthermore, repeat pesticide poisoning would likely lead to a fatal, rather than a non-fatal outcome.

The proportion using medication overdose in the index selfharm episode in Taipei City was lower than the figures observed in Western countries, where approximately $80 \%$ of patients who self-harmed used medication overdose. In contrast, self-cutting was slightly more common in Taipei City than in the West (19.3\% v. 12-15\%). ${ }^{16,20,27}$ Charcoal burning, which accounted for $5.8 \%$ of self-harm in our sample, was rarer in rural Taiwan $(2.9 \%)^{7}$ and is a method rarely used in Western countries. The variations in methods of self-harm may contribute to the area or country differences in risk of self-harm repetitions.

Self-harm using medication overdose and self-cutting/piercing together was associated with higher risk of non-fatal repetition. Of individuals adopting these two methods in their index self-harm episode, 9.1-17.4\% would repeat within 1 year and 14.9-25\% would do so within 3 years. This finding was consistent with a previous study in rural Taiwan in which self-cutting and the use of drugs or other chemicals as means of self-harm increased future risk of non-fatal repetition in a similar manner. ${ }^{7}$ Some clinicians regard self-cutting as a 'manipulative' self-harm act rather than 'real' suicidal behaviour, thereby neglecting their future suicide risk. $^{28}$ However, several recent studies from the West showed that self-cutting significantly increased future risk of suicide mortality, ${ }^{29,30}$ especially among children and adolescents.

The newly introduced aftercare programme for self-harm ( $90 \%$ of patients were followed up as part of this initiative) may have contributed to the lower rate of self-harm repetition in Taipei City. In studies carried out in England, ${ }^{31,32}$ the rate of psychosocial assessment following a self-harm presentation was $50-60 \%$ and the rate of mental health referral was even lower. Indeed, one study from Taiwan has shown that patients who received aftercare services following an episode of self-harm had a significantly reduced risk of suicide when compared with those who did not. ${ }^{33}$ One further explanation for the lower rate of self-harm repetition in Taipei City is the difference in help-seeking behaviour between Eastern and Western countries.

Consistent with previous findings, a history of self-harm is the strongest risk factor for future repetition. Findings in the present study show that the risk of repeat self-harm rises with increasing number of previous episodes. This perhaps provides support for the interpersonal-psychological theory of suicidal behaviour, ${ }^{34}$ which suggests that repeated exposure to self-harm may further reduce one's feeling of fear and pain towards the act, making repetition more likely; effective early intervention in first-episode cases may help break this cycle of behaviour.

It should be noted that the groups at highest risk of suicide (men, older people and those using more lethal methods) ${ }^{15,35-38}$ differed from those who repeated self-harm (i.e. female, younger age groups and those using methods of low lethality). ${ }^{15,39}$ Hence, different targets are required for strategies aiming to prevent suicide from those targeted at reducing repeat non-fatal self-harm.

\section{Clinical implications}

The risk of non-fatal repeat self-harm in Taipei City is lower than in the West. Among patients who repeat within 1 year following an index episode, approximately half do so in the first 3 months, indicating the high-risk and critical period for interventions. Risk of repetition is higher in females than males, but time to repeat is shorter in males. Patients who use medicine overdose or combine self-cutting and medication overdose are more likely to repeat. Number of repeat self-harm presentations also increased the risk of repetition. The group at greatest risk of non-fatal self-harm repetition is distinct from the high-risk group of suicide; hence, risk assessment should be guided by knowledge of the different risk factors for these separate outcomes.

\section{Funding}

The study was supported by Department of Health, Taipei City Government. The funding agency has no role in the design and conduct of the study; collection, management, 
analysis and interpretation of the data; and preparation, review or approval of the manuscript. Y-Y.C. Was supported by the National Science Council, Taiwan (grant number 101-2314-B-532-005-MY2) and the National Health Research Institute, Taiwan (gran number NHRI-EX100-10024PC). C-L.K. and P.S.F.Y. were supported by a GRF grant of Research Grant Council (HKU-784210).

\section{Acknowledgement}

D.G. is a National Institute of Health Research (UK) senior investigator.

Chi-Leung Kwok, BSC (ActuarSc), Paul S. F. Yip, PhD, Hong Kong Jockey Club Center for Suicide Research and Prevention, and Department of Social Work and Social Administration, University of Hong Kong Hong Kong. David Gunnell, MD, PhD, ( Taipei City Psychiatric Center, Taipei City Hospital, and School of Medicine, Taipei Medical University, Taipei, Taiwan; Ying-Yeh Chen, MD, SCD, Taipei City Psychiatric Center, Taipei City Hospital, and Institute of Public Health and Department of Public Health, National Yang-Ming University, Taipei, Taiwan

Correspondence: Dr Ying-Yeh Chen, 309 Songde Road, Taipei City Psychiatric Center, XinYi District, Taipei, Taiwan. Email: ychen@tpech.gov.tw

First received 4 Apr 2013, final revision 19 Oct 2013, accepted 6 Nov 2013

\section{References}

1 Owens D, Horrocks J, House A. Fatal and non-fatal repetition of self-harm Systematic review. Br J Psychiatry 2002; 181: 193-9.

2 Arensman E, Corcoran P, Fitzgerald AP. Deliberate self-harm: extent of the problem and prediction of repetition. In International Handbook of Suicide Prevention: Research, Policy and Practice (eds RC O'Connor, S Platt, J Gordon): 119-32. Wiley-Blackwell, 2011.

3 Windfuhr $\mathrm{K}$, Kapur N. International perspectives on the epidemiology and aetiology of suicide and self-harm. In International Handbook of Suicide Prevention: Research, Policy and Practice (eds RC O'Connor, S Platt, J Gordon): 27-58. Wiley-Blackwell, 2011.

4 Yip PSF, Chen $Y Y$, Yousuf $S$, Lee $C K$, Kawano $K$, Routley $V$, et al. Towards a reassessment of the role of divorce in suicide outcomes: evidence from five Pacific Rim populations. Soc Sci Med 2012; 75 : 358-66.

5 Yip PSF. Towards evidence-based suicide prevention programs. Crisis 2011; 32: 117-20.

6 Mohamed F, Perera A, Wijayaweera K, Kularatne K, Jayamanne S, Eddleston $\mathrm{M}$, et al. The prevalence of previous self-harm amongst selfpoisoning patients in Sri Lanka. Soc Psychiatry Psychiatr Epidemiol 2011; 46: $517-20$

7 Chen VCH, Tan HKL, Cheng ATA, Chen C-Y, Liao L-R, Stewart R, et al. Non-fatal repetition of self-harm: population-based prospective cohort study in Taiwan. Br J Psychiatry 2010; 196: 31-5.

8 Bertolote JM, Fleischmann A, De Leo D, Phillips MR, Botega NJ, Vijayakumar L, et al. Repetition of suicide attempts: data from emergency care settings in five culturally different low- and middle-income countries participating in the WHO SUPRE-MISS Study. Crisis 2010; 31: 194-201.

9 Yip PSF, Callanan C, Yuen HP. Urban/rural and gender differentials in suicide rates: east and west. J Affect Disord 2000; 57: 99-106.

10 Phillips MR, Li X, Zhang Y. Suicide rates in China, 1995-99. Lancet 2002; 359 835-40.

11 Chen YY, Wu KCC, Yousuf S, Yip PSF. Suicide in Asia: opportunities and challenges. Epidemiol Rev 2012; 34: 129-44.

12 Wu KCC, Chen YY, Yip PSF. Suicide methods in Asia: implications in suicide prevention. Int J Environ Res Public Health 2012; 9: 1135-58.

13 Yip PSF, Hawton K, Liu K, Liu KS, Ng PW, Kam PM, et al. A study of deliberate self-harm and its repetition among patients presenting to an emergency department. Crisis 2011; 32: 217-24.

14 Chung $\mathrm{CH}$, Lai CH, Chu CM, Pai L, Kao S, Chien WC. A nationwide, population-based, long-term follow-up study of repeated self-harm in Taiwan. BMC Public Health 2012; 12: 744.

15 Kuo C-J, Gunnell D, Chen C-C, Yip PSF, Chen Y-Y. Suicide and non-suicide mortality after self-harm in Taipei City, Taiwan. Br J Psychiatry 2012; 200: 405-11.
16 Kapur N, Cooper J, King-Hele S, Webb R, Lawlor M, Rodway C, et al. The repetition of suicidal behavior: a multicenter cohort study. J Clin Psychiatry 2006; 67: 1599-609.

17 Lin DY, Wei LJ, Yang I, Ying Z. Semiparametric regression for the mean and rate functions of recurrent events. J R Stat Soc Series B Stat Methodol 2000; 62: $711-30$

18 Cox DR. Regression models and life-tables. J R Stat Soc Series B Stat Methodol 1972; 34: 187-220.

19 SAS Institute. SAS/STAT 9.3 User's Guide: Survival Analysis, Book Excerpt. SAS Publishing, 2011.

20 Colman I, Newman SC, Schopflocher D, Bland RC, Dyck RJ. A multivariate study of predictors of repeat parasuicide. Acta Psychiatr Scand 2004; 109 306-12.

21 Hsueh LM, Tseng HP, Hsieh YW. Factors affect relocation behavior in Taiwan in recent years - the model of household joint decision on moving and destination choice. J Popul Stud 2007; 34: 69-107.

22 Perry IJ, Corcoran P, Fitzgerald AP, Keeley HS, Reulbach U, Arensman E. The incidence and repetition of hospital-treated deliberate self harm: findings from the world's first national registry. PLOS One 2012; 7: e31663.

23 Harriss L, Hawton K. Deliberate self-harm in rural and urban regions: a comparative study of prevalence and patient characteristics. Soc Sci Med 2011; 73: 274-81.

24 Gunnell D, Eddleston M. Suicide by intentional ingestion of pesticides: a continuing tragedy in developing countries. Int J Epidemiol 2003; 32: 902-9.

25 Yip PSF, Caine ED, Kwok RCL, Chen YY. A decompositional analysis of the relative contribution of age, sex and methods of suicide to the changing patterns of suicide in Taipei City, 2004-2006. Inj Prev 2012; 18: 187-92.

26 Lee HL, Lin HJ, Yeh ST, Chi CH, Guo HR. Presentations of patients of poisoning and predictors of poisoning-related fatality: findings from a hospital-based prospective study. BMC Public Health 2008; 8: 7.

27 Bergen H, Hawton K, Waters K, Cooper J, Kapur N. Epidemiology and trends in non-fatal self-harm in three centres in England: 2000-2007. Br J Psychiatry 2010; 197: 493-8.

28 Kapur N, Murphy E, Cooper J, Bergen H, Hawton K, Simkin S, et al. Psychosocial assessment following self-harm: results from the multi-centre monitoring of self-harm project. J Affect Disord 2008; 106: 285-93.

29 Hawton K, Bergen H, Kapur N, Cooper J, Steeg S, Ness J, et al. Repetition of self-harm and suicide following self-harm in children and adolescents: findings from the Multicentre Study of Self-harm in England. J Child Psychol Psychiatry 2012; 53: 1212-9.

30 Bergen H, Hawton K, Kapur N, Cooper J, Steeg S, Ness J, et al. Shared characteristics of suicides and other unnatural deaths following non-fatal self-harm? A multicentre study of risk factors. Psychol Med 2012; 42: 727-41.

31 Bennewith O, Gunnell D, Peters T, Hawton K, House A. Variations in the hospital management of self harm in adults in England: observational study. BMJ 2004; 328: 1108-9.

32 Kapur N, Steeg S, Webb R, Haigh M, Bergen H, Hawton K, et al. Does clinical management improve outcomes following self-harm? Results from the multicentre study of self-harm in England. PloS One 2013; 8: e70434.

33 Pan YJ, Chang WH, Lee MB, Chen $\mathrm{CH}$, Liao SC, Caine ED. Effectiveness of a nationwide aftercare program for suicide attempters. Psychol Med 2013; 43: 1447-54.

34 Joiner TE. Why People Die by Suicide. Harvard University Press, 2005.

35 Hawton K, Zahl D, weatherall R. Suicide following deliberate self-harm: long-term follow-up of patients who presented to a general hospital. Br J Psychiatry 2003; 182: 537-42.

36 Nordstrom $P$, Samuelsson $M$, Asberg $M$. Survival analysis of suicide risk after attempted suicide. Acta Psychiatr Scand 1995; 91: 336-40.

37 Suokas J, Suominen K, Isometsa E, Ostamo A, Lonnqvist J. Long-term risk factors for suicide mortality after attempted suicide - findings of a 14-year follow-up study. Acta Psychiatr Scand 2001; 104: 117-21.

38 Runeson B, Tidemalm D, Dahlin M, Lichtenstein P, Langstrom N. Method of attempted suicide as predictor of subsequent successful suicide: national long term cohort study. BMJ 2010; 341: c3222.

39 Chen VCH, Tan HKL, Chen C-Y, Chen THH, Liao L-R, Lee CTC, et al. Mortality and suicide after self-harm: community cohort study in Taiwan. Br J Psychiatry 2011; 198: 31-6. 